large work, reviewed in this journal on March 3 . The act is regarded as one of harmonising the discrepancies that arise through specialisation of chromatic and motor organs in the male, and of assimilative structures in the female.

In conclusion, we have to regret the absence of an index or of a list of references, but we may recommend the work as an extremely useful and compact summary of recent work on the physiology of the protozoa.

\section{AMATELR ASTRONOMY.}

An Easy and Concise Guide to the Starry Heavens, arranged as a Companion to the Umbrella Star Map and Revolving Star Dome for Insiruction in Astronomy. By D. McEwan. Pp. 137. (London : Kegan Paul, Trench, Trübner and Co., Ltd., Igro.) Price $5 s$.

THE idea of using the concave surface of an umbrella as a star map is excellent, but, of course, not new. The portability and convenience of manipulation of such a stellar guide are obvious advantages, while the aspect in which the constellations are seen, unlike the view in a celestial globe, corresponds to the reality. The actual construction of such a chart of the sky might quite well form part of the practical work of every elementary course of astronomy.

A simple guide to the heavens, to be used in conjunction with, and in explanation of, such an adapted umbrella should be worthy of notice. It is to be regretted that the present book, while pretending and seeming at the first glance to fulfil just such a function, cannot be recommended. Somewhat scrappy and not always trustworthy, it gives the impression of being the work of an amateur.

After a preface and an introduction, chapter i. devotes a page and a half to astronomical magnitudes and units, and also describes a chart of the north circumpolar stars, which is reproduced. The stars contained in the various "segments" of the "Umbrella Star Map" are dealt with in chapter ii. The persistently miscalled "segments" are really the sectors formed by the ribs and circumference of the umbrella. In the text a certain amount of information is given about the constellations and the principal stars as they occur in each "segment," while charts show their relative positions and make a very rough attempt to indicate stellar magnitudes. The scheme to represent magnitude described for the actual umbrella is not in use, apparently, in the companion book. A separate key-map in each case is used to indicate names. A table, giving for each star a serial number, the Greek letter, constellation, magnitude, right ascension, and declination, completes the information for a typical "segment." General astronomical information is introduced relative to special objects as they are encountered, so that, without reference to the index, it is difficult to find the treatment of any particular subject.

The information given is often amateurish and sometimes in error, while plausible misstatements which would trouble a beginner are to be found. The solar spectrum, for example, is "well known to consist of the seven colours," while by observations made through a long tunnel, or from the bottom of a well, "any star coming into the field of view would be seen even in daylight." Under the title "Major Planets" are described Jupiter, Saturn, Uranus, and Neptune, while the "Minor Planets" are Mercury, Venus, and Mars. 'To Jupiter is ascribed only five moons, the date of discovery of the fifth being given.

Chapter iv. describes a folding liey to the "Umbrella Star Map," and the next chapter deais with the solar system in a bald way. In the pages devoted to time, the sun is described as being due east at six o'clock, while amplitude is misdefined in the following chapter.

A section devoted to scouting and an index to constellations bring to a conclusion a book which needs a thorough revision if it is to be of service.

\section{ELEMENTS OF PHYSICS}

(1) A First Book of Physics. By Dr. L. Lownds. Pp. vii + I45. (London: Macmillan and Co., Ltd., I910.) Price is. $6 d$.

(2) An Elementary Text-book of Physics. Part IV. Heat. By Dr. R. W. Stewart. Pp. iv +246. (London: C. Griffin and Co., Ltd., Igro.) Price 3s. 6d. net.

(3) Matriculation Magnetism and Electricity. A Text-book for Use in Schools and Colleges arranged for Modern Methods of Teaching. By Dr. R. H. Jude and J. Satterly. Pp. vii $+4 \mathrm{r}_{5}$. (Cambridge: Universitw 'Tutorial Press, Ltd., r910.) Price $4 s .6 d$. (1) THIS book is intended for those beginning the 1 study of physics. The contents do not cover the whole ground usually dealt with, but are confined to the principles of measurement, mechanics, and heat. The reason given for this is that it is now customary in secondary schools to limit the courses of study to these subjects for the first two years. Students reading this book are expected to be acquainted with the elements of mathematics, and to be able to perform for themselves the numerous experiments described in the text. Descriptive and numerical test questions form the conclusion of each chapter.

There is no doubt it will be found a very useful book. The most pleasing feature is the exactness with which statements are made, at the same time preserving great simplicity of language. Added to this, the printing and diagrams are good, and advantageous use is made of heavy type for the more important statements of principles.

(2) Dr. Stewart's fourth volume is written in much the same style as the three preceding ones. It is suitable for those possessing no previous exact knowledge of the subject of heat. Attention is paid to all the elementary thermal phenomena, the order of treatment being the usual one. What has been said above in reference to Dr. Lownds's book applies also here. Few difficulties should present themselves to an earnest reader of the subject. Here also many experiments are described, but, with the exception of a few worked in the text, examples are absent.

There is rather a surprising omission, however, in the chapter on the transference of heat by radiation. 